Artigo / Article

\title{
Acute myocardial infarction in the hospital and delay in blood transfusion
}

\section{Infarto agudo do miocárdio e sua relação com o retardo transfusional}

Celina R. Bastos

Gerald A. Hoeltge

\begin{abstract}
Peer reviews of hospital transfusion practices rarely screen for under-transfusion, one definition of which is a delay in transfusion that complicates significant myocardial ischemia. A one-year, retrospective review studied the timing of red cell transfusions among medical and surgical patients with secondary diagnoses of acute myocardial infarction. Five possible cases of delayed transfusion were found among 11,197 transfused patients (incidence $=1$ in 2,200 transfusions). Delayed transfusion can complicate a patient's difficult clinical course. Hospital transfusion committees should consider surveying for delayed transfusion in addition to the more common surveys for over-transfusion. Rev. bras. hematol. hemoter. 2005;27(3):175-178.
\end{abstract}

Key words: Blood transfusion.

\section{Introduction}

Blood transfusions save lives. Red cell transfusion is sometimes withheld from patients with life-threatening anemia to avoid the recognized complications of transfusion such as infection, acute lung injury, or fluid overload. Hospital transfusion committees rarely survey for delayed transfusion. To compare transfusion orders with an objective criterion such as hemoglobin concentration is straightforward; to recognize the absence of such an order as an issue of clinical consequence is more difficult. In this study, the relationship between acute myocardial infarction following hospitalization and red cell transfusion was investigated.

\section{Materials and Methods}

The data set for this study was all patients admitted to the hospital in 2003. A total of 642 admissions were coded with secondary diagnoses of acute myocardial infarction. From this base were selected all cases with one or more recorded venous hemoglobin concentrations of $\leq 8.0 \mathrm{~g} / \mathrm{dL}$ $(n=106)$.
Cases for study met the following conditions: [1] There was no transfusion of Red Blood Cells during the first 24 hours after hospital admission; and [2] there was objective evidence of acute myocardial ischemia. Elevation of cardiac enzymes or troponin I and/or electrocardiographic changes formally interpreted as consistent with ischemia were sufficient for inclusion. Patients who declined blood transfusion were excluded from consideration. Also excluded were those cases for which there was no opportunity to transfuse before the anemia was known (for example, hemorrhage in temporal association with cardiopulmonary resuscitation).

\section{Results}

Five cases of unexplained, delayed transfusion were identified using these criteria during 2003. In that year 11,197 patients were transfused. The incidence of delayed transfusion by these criteria was approximately 1 in 2,200 transfused patients.

a. Case 1 was a 72 year old male transferred from a skilled nursing facility due to bronchopneumonia. Past

Department of Clinical Pathology - The Cleveland Clinic Foundation - Cleveland, Ohio

Correspondence address: Gerald A. Hoeltge

Head, Section of Transfusion Medicine - Department of Clinical Pathology, Desk L20

9500 Euclid Avenue

Cleveland, Ohio 44195

(216) 444-2830

E-mail:hoeltgg@ccf.org 
medical history included coronary artery bypass grafting. Following admission his hemoglobin concentration was 9.5 $\mathrm{g} / \mathrm{dL}$, which declined over the next three days. Acute myocardial infarction was diagnosed on the third hospital day by an elevation of troponin T. Transfusion occurred on the fifth hospital day. The patient was discharged to skilled nursing care much improved after a nine-day hospital course.

b. Case 2 was an 85 year old female admitted for fever, shortness of breath, and hypertension (220/100 mmh). The hemoglobin concentration was $8.4 \mathrm{~g} / \mathrm{dL}$. Acute myocardial infarction was diagnosed by elevation of troponin T and CKMB. An acute upper gastrointestinal bleed reduced the hemoglobin concentration (measured at 5.1 the following morning). Transfusion followed. The patient was discharged improved and in a stable condition on hospital day 34 .

c. Case 3 was an 85 year old male with a two-day history of lower gastrointestinal bleeding at presentation. A cecal polyp was diagnosed. An acute hemorrhage reduced the hemoglobin concentration to $6.2 \mathrm{~g} / \mathrm{dL}$. Acute myocardial infarction was diagnosed by elevations of troponin $\mathrm{T}$ and CK-MB. He was subsequently transfused with two units of Red Blood Cells. The patient was discharged in good condition on hospital day 12 .

d. Case 4 is a 59 year old hypertensive, diabetic woman with a remote history of coronary artery disease. A re-do coronary artery bypass graft was performed. Acute myocardial infarction was diagnosed on the third hospital day. The hemoglobin concentration was $7.9 \mathrm{~g} / \mathrm{dL}$. Two units of Red Blood Cells followed. The patient was discharged in good condition after 15 days in the hospital.

e. Case 5 is an 84 year old female with diabetic gangrene of the great toe. Electrocardiographic changes consistent with ischemia were present at the time of admission. The hemoglobin concentration was $7.6 \mathrm{~g} / \mathrm{dL}$. Transfusion was initiated 23 hours after admission. The patient was discharged much improved on hospital day 17.

Graphical representations of their hemoglobin concentrations during their hospitalizations are shown in Figure 1.

\section{Comment}

The most informative data on the clinical outcome of severe anemia comes from patients who decline blood transfusion. Carson and colleagues selected 300 adult, surgical patients with postoperative hemoglobin concentrations of 8.0 or less. Sixteen percent died in the hospital within thirty days of surgery. Mortality varied inversely with hemoglobin, and patients with cardiac or peripheral vascular disease were at a higher risk. ${ }^{1}$ For example, the odds ratio for a drop in hemoglobin concentration from 6.5 to $<4.5$ grams/liter increased the chance of death by more than 20 times even without cardiovascular disease. With cardiovascular disease, a similar blood loss was calculated to be 216 times more likely to result in death than in the general, surgical, untransfused population. ${ }^{2}$

Severe anemia results in myocardial ischemia. In one experimental model Wilkerson et al. hemodiluted seven healthy baboons with 5\% human serum albumin. Control animals underwent similar volume exchange with compatible blood. The difference in cardiac output was significant when the anemia reached $10 \%$ hematocrit. One died at a $6 \%$ hematocrit; the others were sacrificed at $4 \%$. Remarkably, the oxygen extraction ratio remained constant throughout. ${ }^{3}$ Geha and Baue included coronary stenosis in their experimental model. Twelve normal dogs were successively subjected to thirty seconds of coronary occlusion: first with an unoccluded left anterior descending coronary artery, then with it 50\% occluded, and finally with $67 \%$ occlusion. EKG changes were noted at $67 \%$, and compensatory changes to restore myocardial blood flow were inadequate. Hemodiluted to a hematocrit of $20 \%$, EKG changes were seen at only 50 percent stenosis. At $67 \%$ stenosis there was no measurable compensatory mechanism for myocardial recovery. A combination of anemia and coronary stenosis produced the most profound effect. ${ }^{4}$

Fifty-five, healthy volunteers were hemodiluted to a hemoglobin concentration of $5.0 \mathrm{~g} / \mathrm{dL}$ by Leung and coworkers. 5\% albumin and the subject's own platelet-rich plasma was used as diluents. Three subjects developed asymptomatic ST-segment depression. The EKG changes reversed with restoration of their red cell mass. All 55 were without cardiac, pulmonary, or hepatic disease, non-smokers, and on no $\mathrm{CV}$ medications. The point at which anemia produced myocardial changes was unpredictable. ${ }^{5}$

In a large European study involving 3,534 patients from 146 hospital ICUs, it was found that patients who were in the hospital longer or who were older were more likely to be transfused. Daily blood sampling reduced the hemoglobin concentrations for those with a high count on admission; transfusions increased the concentrations. The collective comfort level appeared to be between 10 and $11 \mathrm{~g} / \mathrm{dL}^{6}$

Hébert's group performed a retrospective analysis of 4,470 ICU patients from 6 Canadian hospitals. Transfusion of Red Blood Cells appeared to improve survival in anemic patients with cardiac disease. ${ }^{7}$ The prospective study that followed in 1999 showed that a restrictive strategy of red cell transfusion (maintaining a hemoglobin concentration between 7 and $9 \mathrm{~g} / \mathrm{dL}$ ) was more effective than a liberal strategy (that is, maintaining it between 10 and 12) with regards to survival from critical illness. ${ }^{8}$ The data indicate that the risk of cardiac consequences increase the lower the hemoglobin concentration becomes, but they do not define with precision where that concentration is for any particular patient.

Similar data are available for the anemia of prematurity. A study from Lubeck, Germany looked at 56 low birth weight infants, 19 of whom were transfused because of tachycardia. Increasing the average hemoglobin concentration from 9.4 
to 12.5 increased oxygen delivery, decreased cardiac output, and halved the rate of anaerobic metabolism. The benefit was only evident for those infants whose hearts were stressed. ${ }^{9}$

Using $28 \%$ as an indication for transfusion, ${ }^{10}$ the group from Washington University looked at patients undergoing radical prostatectomy. ${ }^{11}$ This prospective trial compared preoperative autologous blood deposit with acute normovolemic hemodilution (the latter with and without hematinic prophylaxis). Those patients with lower postoperative hematocrits were at greater risk for myocardial ischemia. The combination of this level of anemia and tachycardia tripled the risk of EKG changes consistent with myocardial ischemia.

Using the definition in the present study, the incidence of delayed transfusion in our practice is approximately 4.5 per 10,000 transfused patients. Few other surveys have been published. Mair et al looked at 55 patients with hemoglobin concentrations of less than $7.0 \mathrm{~g} / \mathrm{dL}$ or platelet counts of $<$ $10,000 / \mathrm{uL}$. No case of delayed transfusion was found. ${ }^{12}$ Saxena et al screened for patients with hemoglobin concentrations of $5.0 \mathrm{~g} / \mathrm{dL}$ or less and a similar platelet

Each of the figures that follows traces the patients' hemoglobin with time. The open arrow indicates the time of initial transfusion
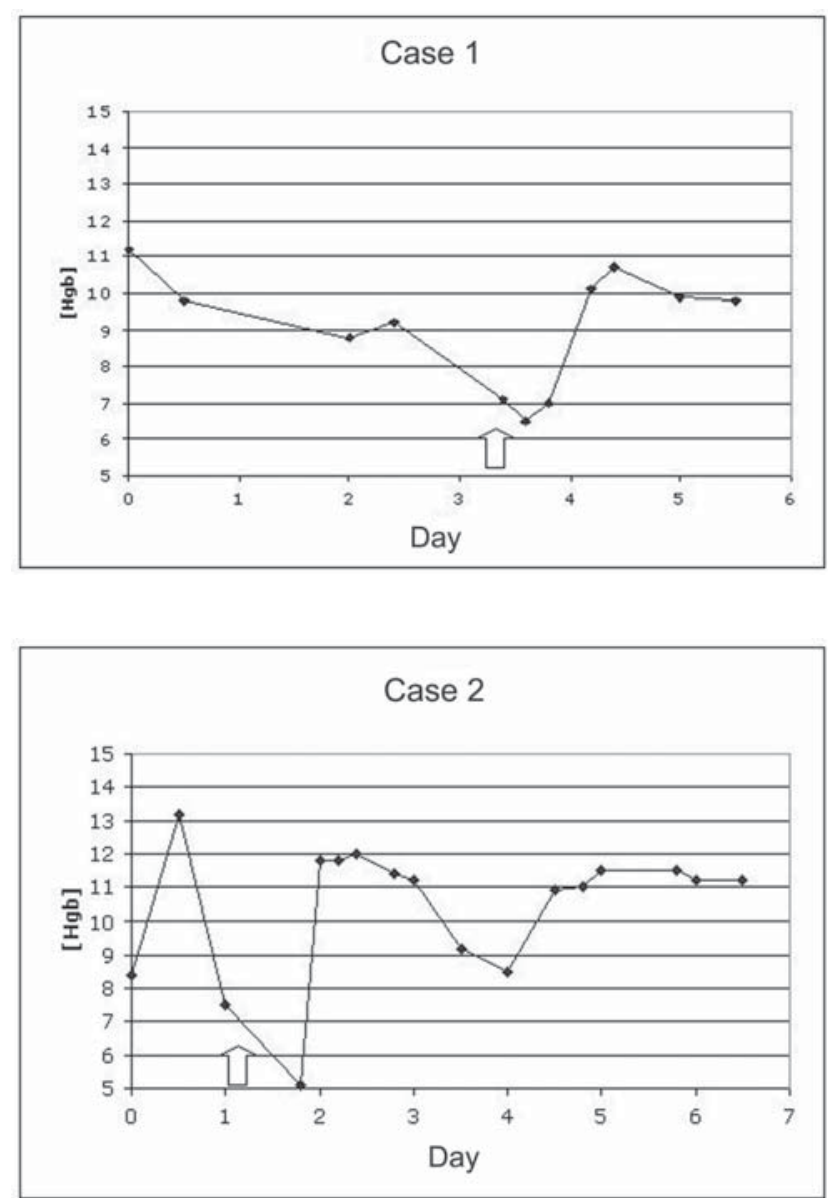

threshold. They found 2 cases over 14 months with this strategy. ${ }^{13}$ Delayed transfusion occurs, but it is rare and detectable only after considerable effort.

We considered an alternate sampling strategy, i.e., to begin with evidence of severe anemia. During the first six months of 2003, there were 23 patients with venous hemoglobin concentrations of $4.0 \mathrm{~g} / \mathrm{dL}$ or less. The strategy was not productive. Five blood samples were taken at or
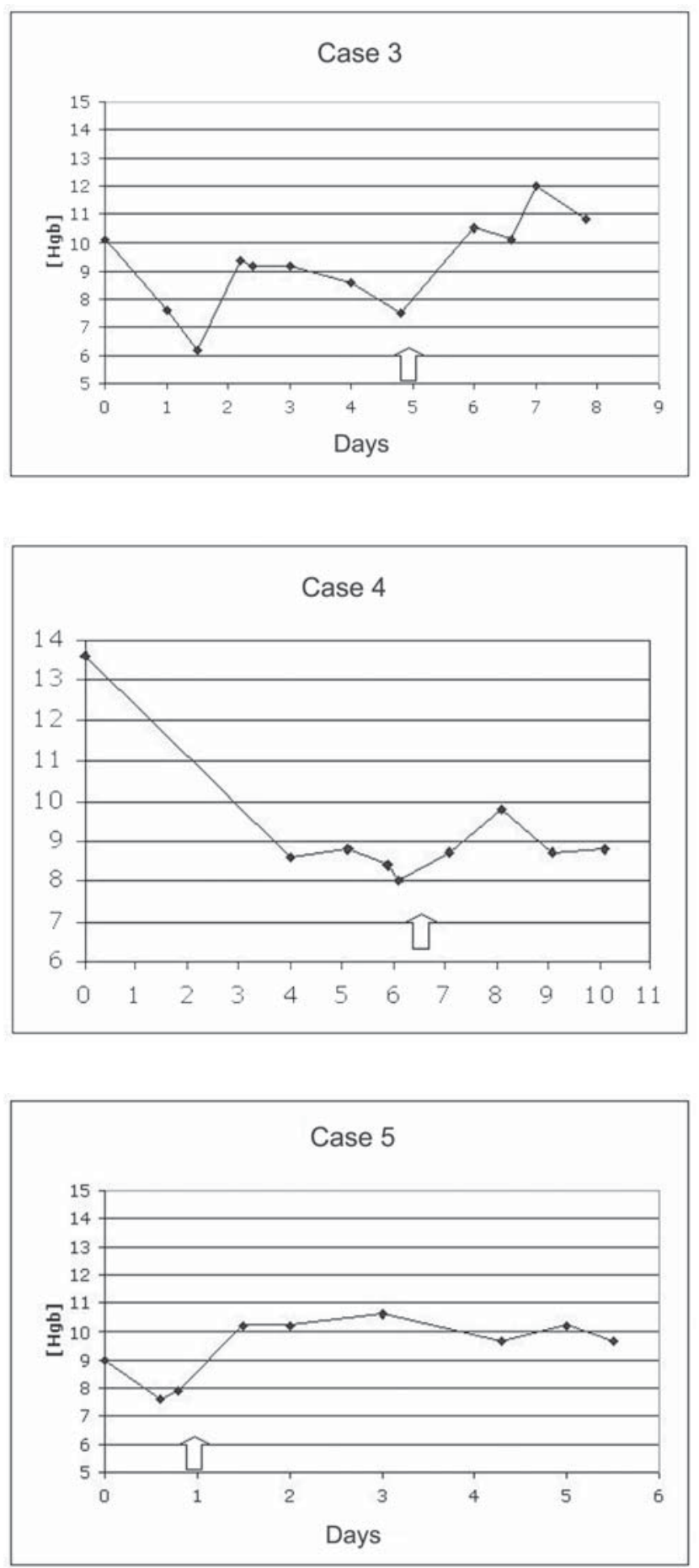
very near the end of life, and 3 were from patients who declined transfusion. Of the remaining 15, 6 were acutely anemia and in 9 the anemia was chronic. All but two, a 21 year old paraplegic with osteomyelitis and a 32 year old with severe iron deficiency anemia, were properly transfused within 24 hours of admission. Both of these patients were stable without transfusion.

There are limited data to suggest that under-transfusion may be more frequent than can be identified by peer reviews. The marginal benefit of transfusion is measurable, even if not identifiable in individual cases. A study of 78,974 Medicare beneficiaries with acute myocardial infarction found that patients with low hematocrits on admission had higher 30day mortality rates. Transfusion below a hematocrit of 33\% lowered the risk of death with or without adjustment for confounding variables. ${ }^{14}$

Physicians involved in peer review know how difficult retrospective interpretation of a medical record for appropriateness is. Two reasonable physicians may look at the same clinical circumstances and develop quite different transfusion strategies. In an attempt to measure the degree of such difference, a group from the University of Wisconsin presented 114 medical school faculty members with 24 hypothetical patient scenarios. Some trends were evident: Transfusion recommendations were more likely with anemia, with symptomatic fatigue, with tachycardia, and in the presence of comorbid conditions. ${ }^{15}$ Even so, the lack of agreement was remarkable. Some practitioners would have transfused every patient, and some would have transfused none of them. The normative practice was between the extremes.

\section{Conclusion}

Under-transfusion is unusual (and no doubt much less common than over-transfusion) but it occurs. The transfusion of each of the patients identified in this study was delayed during a difficult clinical course. It is unknown whether acute myocardial infarctions would have been prevented by blood transfusion earlier in their hospitalization. Whether transfusion would have improved their recovery may even be doubtful. Even so, prudence dictates that to avoid the complications of moderate to severe anemia by blood transfusion is in the best interest of the unstable patient. Hospital transfusion committees commonly survey for overtransfusion. Surveillance activities for delayed transfusion should be considered as well.

\section{Resumo}

Os revisores de prática transfusional hospitalar, raramente avaliOs revisores de prática transfusional hospitalar, raramente avaliam a subindicação transfusional, que propiciam retardo na transfusão possivel de complicação isquêmica miocárdica. Um estudo retrospectivo de um ano de indicações de concentrado de glóbulo entre pacientes clínicos e cirúrgicos com diagnóstico secundário de infarto agudo do miocárdio foi realizado. Cinco casos de possivel retardo na indicação transfusional foram observados em 11.197 pacientes transfundidos (incidência $=1$ em 2.200 transfusões). O retardo na indicação de transfusões pode complicar pacientes em estado grave, sugerindo que os comitês transfusionais devem ficar atentos para o fato, e não só para os casos de excesso de transfusões. Rev. bras. hematol. hemoter. 2005;27(3):175-178.

Palavra-chave: Transfusão de sangue.

\section{References}

1. Carson JL, Noveck H, Berlin JA et al. Mortality and morbidity in patents with very low postoperative Hb levels who decline blood transfusion. Transfusion 2002;42:812-8.

2. Carson JL, Duff A, Poses RM et al. Effect of anaemia and cardiovascular disease on surgical mortality and morbidity. Lancet 1996;348:1.055-60.

3. Wilkerson DK, Rosen AL, Sehgal LR et al. Limits of cardiac compensation in anemia baboons. Surgery 1988;103:665-670.

4. Geha AS, Baue AE. Graded coronary stenosis and coronary flow during acute normovolemic anemia. World J Surgery 1978; 2: 645-651.

5. Leung JM, Wieskopf RB, Feiner J et al. Electrocardiographic STsegment changes during acute, severe isovolemic hemodilution in humans. Anesthesiology 2000;93:1.004-1.010.

6. Vincent JL, Baron J-F, Reinhart K et al. JAMA 2002;288:1.4991.507.

7. Hébert PC, Wells G, Tweeddale M et al. Does transfusion practice affect mortality in critically ill patients? Am J Respir Crit Care Med 1997; 155:1.618-1.623.

8. Hébert PC, Wells G, Blajchman MA et al. A multicenter, randomized, controlled clinical trial of transfusion requirements in critical care. New Engl J Med 1999;340:409-417.

8. Moller JC, Schwarz U, Schaible et al. Do cardiac output and serum lactate levels indicate blood transfusion requirements in anemia of prematurity? Intensive Care Med 1996;22:472-476.

9. Nelson AH, Fleisher LE, Rosenbaum SH. Relationship between postoperative anemia and cardiac morbidity in high-risk vascular patients in the intensive care unit. Crit Care Med 1993;21:860-866.

10. Hogue CW, Goodnough LT, Monk TG. Perioperative myocardial ischemic episodes are related to hematocrit level in patients undergoing radical prostatectomy. Transfusion 1998;38:924-931

11. Mair B, Agosti SJ, Foulis PR et al. Monitoring for undertransfusion. Transfusion 1996;36:533-5.

12. Saxena S, Wehrli G, Makarewicz K et al. Monitoring for underutilization of RBC components and platelets. Transfusion 2001; 41:587-90.

13. Wu W-C, Rathore SS, Wang Y et al. Blood transfusion in elderly patients with acute myocardial infarction. N Engl J Med 2001; 345:1.230-1.236.

14. Brown RL, Brown RL, Edwards JA, Nutz JF. Variation in a medical faculty's decisions to transfuse; implications for modifying blood product utilization. Medical Care 1992;30:1.083-1.096

Avaliação: Editor e dois revisores externos

Conflito de interesse: não declarado

Recebido: 21/09/2005

Aceito após modificações: 28/09/2005 